\title{
Caminhos desiguais: um estudo da trajetória das pessoas com deficiência pela educação e mercado de trabalho em um dos estados mais ricos da federação
}

\author{
Maria Helena Scalabrin \\ Alzira Lobo de Arruda Campos
}

Caminhos desiguais: um estudo da trajetória das pessoas com deficiência pela educação e mercado de trabalho em um dos estados mais ricos da federação

Resumo: A inclusão de Pessoas com Deficiência no mercado de trabalho é neste estudo analisada pelo viés da aprendizagem e da economia do trabalho, uma vez que a baixa escolaridade desses profissionais vem sendo apontada pelas organizações como entrave maior para as contratações. Por meio da análise das políticas públicas educacionais e organizacionais de quatro regiões do Estado de São Paulo, pesquisas de campo (54), análises das informações do Ministério do Trabalho, e Fazenda, Fundação Seade, IBGE/MUNIC, e Empresas do Estado de São Paulo, percebem-se inconsistências entre discursos, idealizações e práticas inclusivas. Os resultados indicam que as contratações se encontram em patamares inferiores aos objetivos oficiais propostos e às potencialidades do Estado. As políticas municipais para a educação e aprendizagem organizacional inclusiva são incipientes. Os empregos oferecidos destinam-se, via de regra, para cargos operacionais ou auxiliares, de pouca complexidade, mesmo para profissionais tenham concluído estudos universitários.

Palavras-Chave: Pessoas com deficiência. Aprendizagem e inclusão profissional. Mercado de trabalho. Políticas públicas.

Uniqual roads: a study of the trajectory of persons with disabilities for education and the labor market in one of the richest state in the country.

Abstract: The inclusion of People with Disabilities (PcD) in the labor market is considered in this study by the bias of learning and labor economics, since the low education has been argued by organizations as the biggest obstacle to hiring these professionals. Through the analysis of educational and organizational policies of four regions of the State of São Paulo, field research (54), analysis of the Ministry of Labor information, and Finance, Foundation SEADE, IBGE/MUNIC and Companies settled in the State was observed inconsistencies between speeches idealizations and inclusive practices. The results indicate that the practice of hiring are at levels lower than those objectives officially proposed and the potential hiring of the State. Municipal policies for education and inclusive organizational learning are still incipient. The jobs offered are, usually, those of operational levels and auxiliary, both of low complexity, even for professionals that have completed their higher education.

Keywords: Persons with disabilities. Learning and professional inclusion. Labor market. Public policies.

Esta obra foi licenciada sob uma Licença Creative Commons - Atribuição 3.0 Não Adaptada. 


\section{Introdução}

No dia 10 de junho de 2015, depois de uma tramitação de 12 anos, o Senado aprovou o Estatuto da Pessoa com Deficiência. O Estatuto consolida e ampliam direitos, como o pagamento do auxílio-inclusão e a reserva de vagas em universidades, assim como no mercado de trabalho e unem dois pontos básicos: o direito à educação e ao trabalho. Na verdade é um verdadeiro nó górdio, a ser cortado pela Lei e pela prática social, uma vez que o direito à Educação aparenta ser consensual, mas o direito ao trabalho ainda está em processo de ajustamentos na economia.

Trata-se de questão de invulgar complexidade, quando se pensa que a Educação é vista universalmente como poderosa ferramenta de promoção social, e os indivíduos portadores de deficiência, como sujeitos de maior atenção da ação educativa. Por outro lado, a inclusão desses indivíduos na esfera de produção é preceito constitucional, uma vez que garante o acesso de todos, sem distinção de raça gênero ou qualquer outra característica discriminatória.

A Lei no 13.146, sancionada em 6 de julho de 2015 no Art. $2^{\circ}$ define como Pessoa com Deficiência,

(...) aquela que tem impedimento de longo prazo de natureza física, mental, intelectual ou sensorial, o qual, em interação com uma ou mais barreiras, pode obstruir sua participação plena e efetiva na sociedade em igualdade de condições com as demais pessoas.

$\mathrm{O} \S 1^{\circ}$ da Lei supracitada, determinada que,

(...) a avaliação da deficiência, quando necessária, será biopsicossocial, realizada por equipe multiprofissional e interdisciplinar e considerará: I - os impedimentos nas funções e nas estruturas do corpo; II - os fatores socioambientais, psicológicos e pessoais; III - a limitação no desempenho de atividades; e IV - a restrição de participação.

Este artigo, à luz da legislação pertinente, procura contribuir para esclarecer a questão, examinando políticas de Estado pertinentes à inclusão de Pessoas com Deficiência no mercado de trabalho, do ponto de vista da escolaridade e da oferta de empregos a esses cidadãos. Para tanto, selecionaram-se quatro regiões do Estado de São Paulo, como continente empírico, que permite a análise comparativa entre dois grupos, que apresentam, respectivamente, maior e menor grau de desenvolvimento.

Adotou-se como método de estudo a filogênese histórica, no contexto amplo da marcha da cidadania, a partir de premissas filosóficas que pavimentaram a história de longa duração sobre o tratamento e a visão que a sociedade tem de seus membros, considerados incompetentes para a assunção de valores ideologicamente estabelecidos.

Fenômenos sociais amplos e complexos, como os que envolvem Estado, Sociedade e Família, entrelaçam-se numa complicada trama do tecido social, cujos fios condutores passam pelo conceito mausseano de fato social - um conjunto de fatos, em que tudo "se mistura, naquilo que constitui a vida propriamente social" (MAUSS, 2003, p.187). Outra contribuição vem de Lev Vygotski (2004) que aborda a epistemologia e o dualismo nas ciências sociais. Para o autor, a elaboração de um instrumento de 
pesquisa, dentro da perspectiva histórico-social, deve superar os reducionismos presentes nas metodologias teóricas e empíricas.

A teoria vygotskyana baseada em conceitos provenientes do materialismo histórico atribui papel central do aprendizado no desenvolvimento humano. Vygotsky considera que todo fenômeno tem uma história, sujeita a modificações quantitativas e qualitativas, que podem explicar a evolução dos processos psicológicos elementares para processos mais complexos, uma vez que as mudanças na sociedade produzem mudanças singulares. A atividade humana modifica a natureza, ao criar a cultura, transformando o habitat para atender às necessidades básicas, ao mesmo tempo em que o homem transforma a si mesmo.

\section{Metodologia}

A partir dos conceitos acima, este estudo adota a interdisciplinaridade, considerando várias categorias de análises para a apreensão do processo de inclusão da Pessoa com Deficiência na educação e na esfera de produção. Em torno desse eixo, organizam-se as seguintes fases metodológicas: 1) revisão da literatura, com abordagem interdisciplinar; 2) critérios para a escolha do método e o cotejo das abordagens; 3) definição dos sujeitos de pesquisas; 4) pesquisas exploratórias que partem da análise das variáveis socioeconômicas para estabelecer uma base de dados comparativos e se chegar aos fins pretendidos. 5) Pesquisa de campo, tendo por referência a Instrução Normativa 098/2012 do Ministério do Trabalho. Entrevistados: Secretárias de Assistência e Promoção Social, Desenvolvimento Econômico; Diretora Regional do Ministério do Trabalho, Promotor Público, Gerentes de Recursos Humanos das Contratantes e Profissionais com Deficiência. Foram realizadas ao todo 54 entrevistas. Completaram as análises, informações obtidas junto ao Ministério do Trabalho (RAIS/CAGED, 2012, 2013,2014), Secretaria do Desenvolvimento Econômico (MF) e IBGE/MUNIC.

\section{Primeiro Percurso Inclusivo: acesso à educação.}

De acordo com Aristóteles, para o homem ser bom e vivenciar o bem comum é preciso construir uma sociedade onde ele possa viver esse bem. Nesse sentido, uma sociedade somente é boa se ela propicia essa vivência do bem público, que se traduz por acesso à cultura, lazer, esportes, educação e a um trabalho digno (GOMES, 2010). Uma sociedade é inclusiva quando, no início do processo de convivência e aprendizagem, as diferenças se encontram, se reconhecem e se respeitam mutuamente.

No Brasil, marcado por desigualdades extremas, o caminho para a cidadania está em curso, tendo conseguido conquistas significativas para diversas minorias, por meio do estabelecimento de políticas de Estado, que vêm ao encontro das necessidades reais da sociedade. Dentre essas necessidades, figura a educação pública de qualidade, como uma das demandas mais urgentes da atualidade, à qual a nação vem procurando atender por meio do estabelecimento de uma série de Ações Afirmativas.

O acesso à escola é garantia constitucional. O Compromisso de Dakar, Educação para Todos (2000), ratificado pelo Brasil, aponta para os direitos a uma educação que satisfaça as necessidades básicas de aprendizagem, no melhor e mais pleno sentido do termo. Esse Compromisso previa as ações que deveriam ter sido alcançadas até o ano de 
2015. Além disso, sublinha os cuidados devidos às crianças mais vulneráveis, nas quais, evidentemente alinham-se os indivíduos com deficiência. O Decreto 6.094/2007, que tratou da implementação de um plano de metas, determinou - em regime de colaboração entre a União, Estados e Municípios, com a participação das famílias e da comunidade, mediante programas de assistência técnica e financeira - a mobilização coletiva pela melhoria da qualidade da educação básica.

O documento acolhe um Plano de Ações Articuladas (PAR), com uma gestão visando à universalização e melhoria da Educação Básica, assegurando a equidade nas condições de acesso e permanência e conclusão em idade adequada. $\mathrm{O}$ plano prevê a formação dos professores da educação básica para atuação em educação especial, escolas de campo, comunidades quilombolas ou indígenas (BRASIL/MEC. 2007).

Todavia, entre a letra da Lei (CF, LDB/PNE), a ação do Executivo (manifestada por Decretos e Atos Normativos) e a sua prática em sala de aula, mais de duas décadas se passaram, sem resultados efetivos, ou seja, a inclusão plena, que deveria iniciar-se nos bancos da escola.

As diretrizes gerais vêm sendo atendidas, mas os recursos destinados voltados à capacitação e à contratação de professores especializados são ainda insuficientes. Na opinião de Cesar Callegari (2015), membro do Conselho Nacional de Educação - os resultados da primeira edição da Avaliação Nacional de Alfabetização (ANA) realizada pelo INEP em 2013, junto a 2.600.000 alunos concluintes do terceiro ano do ensino fundamental - revelou uma situação crítica: em cada quatro crianças, uma chega a essa fase sem estar alfabetizada. No Pará, $70 \%$ desses alunos não sabem escrever; em Alagoas, metade não sabe ler, e em São Paulo o problema é também muito grave (FOLHA, Tendências e Debates, 03.06.2015).

A avaliação acima fica ainda mais sombria quando se trata de atendimento educacional especializado. Nesse setor, ações básicas para a implementação das propostas encontravam-se em estágio inicial, pois a inclusão em salas regulares de ensino, mesmo constando da Lei de Diretrizes e Bases da Educação Nacional de 1996 (LBB 9.394), até fins de 2010, continuava muito baixa (GOMES, 2010).

Quando uma política pública, como a educação especial, não é implementada, são anulados os demais vetores inclusivos, ao não facultar o acesso ao desenvolvimento pleno, que se inicia pela educação, e é, em tese, seguido pelo direito ao trabalho. Se uma criança não convive com a diferença, fica difícil, na idade adulta, conviver com ela em um ambiente de trabalho.

A tabela a seguir, ilustra o número de empregos de Pessoas com Deficiência por grau de instrução e por tipo de deficiência.

\section{Tabela 01 - BRASIL: Pessoas com Deficiência Contratadas Segundo Instrução e Tipologia da Deficiência.}

\begin{tabular}{l|r|r|r|r|r|r|r|l}
\hline & Física & $\begin{array}{l}\text { Auditiv } \\
\text { a }\end{array}$ & $\begin{array}{l}\text { Visua } \\
\text { l }\end{array}$ & $\begin{array}{l}\text { Intelectu } \\
\text { al }\end{array}$ & $\begin{array}{l}\text { Múltipl } \\
\text { a }\end{array}$ & $\begin{array}{l}\text { Reabilitad } \\
\text { os }\end{array}$ & $\begin{array}{l}\text { Total de } \\
\text { Deficient } \\
\text { es }\end{array}$ & $\begin{array}{l}\text { Total } \\
\text { Empreg } \\
\text { os }\end{array}$ \\
\hline \multicolumn{1}{c|}{ Analfabeto } & 792 & 643 & 153 & 1153 & 114 & 122 & 2.977 & 163.039 \\
\hline $\begin{array}{l}\text { Até o 5 } \\
\text { Fund. }\end{array}$ & 6.654 & 4.646 & 1.225 & 3.708 & 404 & 1.051 & 17.688 & 1.514 .951 \\
\hline $5^{\circ}$ ano completo do E. & 7.008 & 4.401 & 1.121 & 1.450 & 333 & 1.503 & 15.816 & 1.684 .460 \\
\hline
\end{tabular}


Caminhos desiguais: um estudo da trajetória das pessoas com deficiência pela educação e mercado de trabalho em um dos estados mais ricos da federação

\begin{tabular}{|c|c|c|c|c|c|c|c|c|}
\hline & & & & & & & & \\
\hline F. & & & & & & & & \\
\hline $\begin{array}{l}6^{\circ} \text { ao } 9^{\circ} \text { ano Incomp. } \\
\text { E.F. }\end{array}$ & 15.197 & 9.178 & 2529 & 4.689 & 559 & 3036 & 38.188 & 3.200 .199 \\
\hline Ensino Fund. Completo & 18.039 & 9.754 & 3006 & 3.410 & 714 & 4.248 & 39.171 & 5.598 .269 \\
\hline $\begin{array}{l}\text { Ensino Médio } \\
\text { Incompleto }\end{array}$ & 13.954 & 6.993 & 2.548 & 2.997 & 442 & 2.296 & 29.230 & 3.723 .884 \\
\hline $\begin{array}{l}\text { Ensino Médio } \\
\text { Completo }\end{array}$ & 82.821 & 30.721 & $\begin{array}{r}15.46 \\
3\end{array}$ & 7269 & 2004 & 15.771 & 154.056 & $\begin{array}{r}22.137 .70 \\
6\end{array}$ \\
\hline $\begin{array}{l}\text { Educ. Superior } \\
\text { Incompleta }\end{array}$ & 9033 & 2.416 & 1.720 & 250 & 159 & 1.454 & 15.032 & 1.879 .225 \\
\hline $\begin{array}{l}\text { Educ. Superior } \\
\text { Completa }\end{array}$ & 27.966 & 9.326 & 5.740 & 406 & 761 & 4.440 & 48.639 & 9.046 .700 \\
\hline Total & $\begin{array}{r}181.46 \\
4\end{array}$ & 78.078 & $\begin{array}{r}33.50 \\
5\end{array}$ & 25.332 & 5.490 & 33.928 & 357.797 & $\begin{array}{c}48.948 .43 \\
3\end{array}$ \\
\hline
\end{tabular}

Fonte:. MTE/RAIS 2013/CGET/DES/SPPEMTE.

Segundo o IBGE (Censo de 2010) 2,8 milhões de Pessoas com Deficiência no Brasil têm ensino superior completo, porém desse total, apenas 48.639 (MTE/RAIS, 2013) estavam inseridas no mercado de trabalho. As últimas publicações abrindo os dados da RAIS por especificidade ocorreu no ano pesquisado: 2013. Este é um problema com que se deparam os pesquisadores: atraso nas divulgações das informações.

\section{$2^{\circ}$ Percurso: Acesso ao Trabalho}

A Declaração dos Direitos Universais, a Organização Internacional do Trabalho, os Tratados e Acordos Internacionais, além de legislações específicas dos países signatários, apontam para os direitos dos trabalhadores, que não podem ser entendidos como direitos a ser acionados contra o Estado, mas que se realizam através do Estado (LIMA, Jr. J. B., 2001).

Essa regra, entretanto, não vem acompanhada da imposição aos empregadores de contratar, salvo nas especificidades da lei (Lei de Cotas). Mesmo assim, faculta-se à empresa a escolha dos profissionais a contratar, uma vez que não se pode exigir do Estado a supressão de eventuais carências (LIMA, 2001; KRELL, 2013).

O Estado, todavia, como agente público, deve criar condições para a materialização desses direitos. Da ausência do Estado em cumprir o pressuposto básico, que é a oferta educacional, decorreram, como justificativas para a baixa contratação, a baixa formação dos profissionais com deficiência. A falta de escolaridade apropriada, segundo os contratantes, foi um dos aspectos que fez com que o direito ao trabalho de Pessoas com Deficiência ficasse socialmente submergido, até o ano de 2004.

Tal fato foi parcialmente confirmado nas pesquisas aqui realizadas, pois a oferta marcou-se sensivelmente pela demanda de mão de obra operacional, pressupondo ensino fundamental e médio completos, em contradição com a força de trabalho disponível no mercado, uma vez que até essa data a inclusão ainda não havia ocorrido no Ensino Público. Todavia, Pessoas com Deficiência, cujas famílias têm maior poder aquisitivo, alcançaram estudos ulteriores, sem encontrar, porém, organizações que contratassem profissionais com deficiência, com as qualificações de que dispunham. Assim, não se sujeitaram aos postos de trabalhos sem qualificação, que lhes eram ofertados, permanecendo desempregados. 
O trabalho, como espaço de realização pessoal e social do indivíduo, passou por inúmeras transformações. A expressão Decent Work surgiu em 1999, como síntese das proposições da OIT (Organização Internacional do Trabalho), para trabalhadores de todo o mundo, visando a garantir a justiça social (AMORIM et al, 2010). O termo implica atenção aos princípios fundamentais da OIT - apoio às políticas sociais de emprego e renda, abertura e permanência de um diálogo social entre o mundo empresarial e os trabalhadores. No final do século XX, valorizaram-se mais os aspectos econômicos, face à celeridade das transformações ocorridas no mundo do trabalho e no financeiro (MORIN, 2011).

A antropologia do trabalho sugere que a dimensão especificamente humana "decente" não é nova nem excepcional. Os conceitos de atividade e tarefa remetem ao real, ao que resiste à simples aplicação de recomendações, quer no plano individual, quer no coletivo. Distinguem-se homens e mulheres em função das "modalidades particulares na construção dos coletivos" (DEJOURS, 1999, p. 161-2).

Nos pressupostos da racionalidade, da análise dos movimentos históricos e implicações na área do trabalho, Dejours (1999, p. 161-2.) busca compreender o sofrimento que pode decorrer do trabalho, podendo afetar a integridade física e mental dos trabalhadores, no que ele qualifica como banalização da injustiça social. Isso ocorre quando fatores negativos estão presentes no trabalho (medo, indiferença, covardia, entre outros sentimentos).

O trabalho situa-se numa teoria social renovada pela teoria da ação, levando em conta, não apenas normas, mas também valores. A investigação teórica deve conduzir pesquisas sobre a teoria do sujeito, articulada à psicologia do trabalho e da ação. Considerado como atividade central na vida humana (DEJOURS, 1999, p. 26), jamais neutra, o trabalho é gerador de saúde, contribuindo para a constituição do sujeito, ou é fator de desestabilização, quando se transforma em fonte de enfermidades. Observa-se a centralidade do trabalho, na mediação entre o singular e o coletivo, articulando as esferas, social e a privada. A centralidade do trabalho manifesta-se mesmo na sua ausência, traduzindo-se nas carências do indivíduo desempregado (GOMES, 2014).

O caráter paradoxal do trabalho está na mediação das relações de dominação, mas também possibilita a reapropriação de direitos. Amartya Sen (2000) acusa um afastamento entre a ética e as decisões econômicas. De acordo com o economista, as políticas do trabalho deveriam ter como foco, além da liberdade, a promoção da capacidade geral dos trabalhadores, fornecendo-lhes facilidades materiais $\mathrm{e}$ oportunidades de acesso à educação e à saúde.

Os direitos humanos, dentre eles, o direito à educação e ao trabalho, devem ser considerados como a concretização histórica do princípio da dignidade, como também o resguardo da personalidade.

Gisela Bester (2007) afirma que direitos humanos e direitos de personalidade se equivalem. Quando o tema é a personalidade humana, não se podem limitar ou enquadrar esses direitos. Assim, o direito de personalidade encontra reconhecimento, não só no princípio da dignidade da pessoa, ou de uma existência digna, mas na possibilidade de sua realização. Direitos humanos e direitos fundamentais não são apenas princípios que resumem a concepção de mundo e conformam uma determinada ideologia política, mas são atos obrigatórios, voltados à concretização dos ideais de convivência digna, livre e igual para todos (NUNES RIZZATO, 2011; SARLET, 2008). 
Na concepção teleológica, a dignidade é um predicado do Ser que não admite equivalências, não tem preço, não pode ser mensurada, só existe no que é humano e, portanto, traz em si o valor supremo de toda e qualquer ordem social e jurídica, pois todos os demais direitos são regidos por essa concepção (KANT, 1974). Enquanto o preço representa um valor exterior, com interesses específicos, a dignidade representa um valor interior, imensurável. Uma vida digna subentende uma ordem econômica que orbite em torno das condições para obtê-la; uma ordem social que tenha por foco a realização da justiça social; e, por último, uma ordem educacional que garanta o preparo da pessoa para o exercício pleno da cidadania. No princípio da vida digna, insere-se a solidariedade, sem a qual os pressupostos inclusivos são difíceis de concretizar (BESTER, 2009).

A solidariedade entra no processo da inclusão como a identificação do outro em seu direito à personalidade, pois ele existe enquanto ser singular, mas também se insere no todo enquanto alma, dentro do princípio da unidade na diversidade. Distinto na forma, nas manifestações e nos direitos de persona, mas uno enquanto essência.

De posições teleológicas, como as acima, decorre o eixo desta análise, que verifica os conceitos de direitos à cidadania plena à luz da realidade existencial de Pessoas com Deficiência no Brasil. A oferta da educação é premissa básica para a sua inserção no mercado de trabalho. Nesse sentido, observa-se que, dos 49.571.260 milhões de empregos formais nos 2014, apenas 381.322 postos foram preenchidos por Pessoas com Deficiência, que possuíam, em sua maioria, o ensino médio incompleto. Outro dado relevante é observado entre 2007 e 2011: houve uma redução nos estoques de emprego para Pessoas com Deficiência, acusando a maior queda no ano de 2009 $(8,27 \%)$, conforme demonstrado na tabela a seguir. Observar que estes números guardam conformidade com a política pública de inclusão educacional.

Tabela 2- BRASIL. Evolução no Estoque de Empregos das Pessoas com Deficiência.

\begin{tabular}{l|l|r|r|r|r|r|r|r}
\hline Exercícios & 2007 & 2008 & 2009 & 2010 & 2011 & 2012 & 2013 & 2014 \\
\hline Estoques: 348.848 & 323.219 & 288.593 & 306.013 & 325.291 & 330.296 & 358.738 & 381.322 \\
\hline
\end{tabular}

Fontes: MTE/RAIS/FIPE/MODEN/2007, 2008, 2009, 2010, 2011/2012, 2013, 2014. Até o momento desta publicação o TEM não havia divulgados os micro dados da RAIS 2014 e 2015.

Do estoque de empregos de 2014, as contratações de Pessoas com Deficiência ocuparam apenas $0,77 \%$. O Estado, de certa forma, apresenta-se resguardado nesse quadro, pela isonomia imposta nas regras classificatórias dos concursos públicos. O setor privado está sob imposição direta da lei, mas reporta-se à qualificação profissional como requisito mínimo.

Observa-se que não se pode exigir do Estado o cumprimento da contratação. No setor privado, as regras para a oferta de cargos são livres, desde que se cumpram os percentuais legais. Assim se instalou um círculo vicioso. Os cargos ofertados requerem qualificação até o Ensino Médio completo, enquanto que a população, capaz de atender a esses postos de trabalho, não recebeu formação educacional apropriada. Agrava o quadro quando observado que PcDd com diplomas universitários não encontram vagas compatíveis com sua qualificação. 
Quando se analisa a inclusão da Pessoa com Deficiência em perspectiva nacional, nos pressupostos das políticas geradas pelos municípios brasileiros, conclui-se que, de um total de 5.570, apenas 1.349 desenvolveram ações para a geração de trabalho e renda. Decompondo esse último número, verifica-se que, dentre esses municípios, 1.016 deles estavam na categoria de pequenos, com até 50.000 habitantes, em sua maioria, situados na região Sudeste, 433, seguidos da Nordeste. 360; Sul, 336; CentroOeste, 139 e Norte, 81 (IBGE/MUNIC/ 2012). Neste estudo procurou-se os micro dados econômicos e do trabalho que mais se aproximavam das datas bases deste estudo, uma vez que as divulgações dos mesmos se dão com muito atraso e em distintos tempos.

O Mirante da Inserção fez uma análise da inclusão e considerou que o Estado de São Paulo mais rico da Federação não conseguiu imprimir um ritmo crescente de contratações de profissionais com deficiência, apresentando resultados considerados "pífios": apenas 94.884 contratados, mas com um potencial de 192.048 contratações. Nesse número estão incluídos 22.574 profissionais com deficiência, contratados por empresas com menos de 100 funcionários, desobrigadas, portanto, da contratação (MTE/SSP, 2011, Boletim de Análise no 6). É um aspecto que deve ser considerado pelos legisladores no aperfeiçoamento da inclusão, pois segundo a Secretaria de Desenvolvimento Econômico do Ministério da Fazenda, 46,71\% postos de trabalho em 2014 estiveram em empresas de pequeno e médio portes, de um total de $\mathbf{5 0 . 7 4 4 . 7 6 1}$ (2013) e 49.568.260 (2015).

Tabela 03 - BRASIL: Total de Vínculos Efetivos por Empresa (2013-2014)

\begin{tabular}{|c|c|c|c|c|}
\hline Empresa (no empregados) & 2013 & $\%$ & 2014 & $\%$ \\
\hline até 4 & 4.120 .490 & & 4.248 .594 & \\
\hline De 05 a 09 & 4.080 .911 & & 4.187.589 & \\
\hline De 10 a 19 & 4.560 .085 & & 4.682 .083 & \\
\hline De 20 a 49 & 5.847 .930 & & 5.952 .628 & \\
\hline De 50 a 99 & 4.049 .290 & & 4.083 .085 & \\
\hline Sub Total & 24.457 .346 & $48,20 \%$ & 23.153.979 & $46,72 \%$ \\
\hline 100 a 249 & 5.152 .902 & & 5.162 .906 & \\
\hline De 250 a 499 & 4.169 .913 & & 4.176 .806 & \\
\hline De 500 a 999 & 4.110 .102 & & 4.094 .605 & \\
\hline 1000 ou mais & 12.854 .498 & & 12.979 .964 & \\
\hline Sub-total & 26.287 .415 & $51,80 \%$ & 26.414.281 & $53,28 \%$ \\
\hline
\end{tabular}

Fonte Secretaria de Política Econômica do Ministério da Fazenda, 2013/2014.

As pequenas e médias empresas, que já contratam espontaneamente, conforme constatado em pesquisas, poderiam ser mais inclusivas se pudessem contar com equipamentos e adaptações necessárias, pois nem sempre dispõem de capital para esse fim.

Traz-se para esse estudo um levantamento efetuado pela Federação das Indústrias do Estado de São Paulo (FIESP), demonstrando algumas situações dispares na inclusão, conforme tabela que segue. 
Tabela 04 - FIESP: Participação das Pessoas com Deficiência no Emprego

Formal, Segundo as Regiões Administrativas e Lei de Cotas (2010);

\begin{tabular}{|c|c|c|c|}
\hline $\begin{array}{l}\text { Região Metropolitana/ } \\
\text { Administrativa }\end{array}$ & PcDs contratados & Total Empregos & $\begin{array}{c}\text { Variação } \\
\%\end{array}$ \\
\hline Araçatuba & 652 & 61.377 & 1,06 \\
\hline Barretos & 261 & 30.853 & 0,85 \\
\hline Bauru & 914 & 104.468 & 0,87 \\
\hline Campinas & 9.059 & 713.155 & 1,17 \\
\hline Central & 1.208 & 94.299 & 1,28 \\
\hline Franca & 444 & 64.254 & 0,69 \\
\hline Marília & 684 & 61.759 & 1,11 \\
\hline Presidente Prudente & 1.053 & 48.172 & 2,19 \\
\hline Santos & 468 & 55.691 & 0,84 \\
\hline São José dos Campos & 3.326 & 169.787 & 1,96 \\
\hline São José do Rio Preto & 672 & 110.601 & 0,61 \\
\hline São Paulo & 19.091 & 1.669 .770 & 1,14 \\
\hline Sorocaba & 2.622 & 232.274 & 1,13 \\
\hline
\end{tabular}

A Região metropolitana mais inclusiva $(2,19 \%)$ é Presidente Prudente, muito embora o total de empregos da região esteja nos níveis mais baixos nos estoques de empregos.

\section{Pesquisas Exploratórias e de Campo}

Uma vez estabelecido que a educação inclusiva ocorre no Brasil com graves falhas estruturais e recursos humanos inadequados à realização da tarefa, passa-se a verificar como esses profissionais, na vida adulta, vêm-se incluídos no mercado de trabalho.

Como recortes empíricos foram selecionados quatro regiões paulistas: Alta Paulista e Registro, com baixa oferta de trabalho e baixo desenvolvimento econômico; e Região Metropolitana de Campinas e ABC, com alto desenvolvimento e alta demanda de trabalho. A diversidade dos entrevistados corresponde ao interesse em conhecer os diferentes pontos de vista.

Modalidade da pesquisa de campo e sujeitos das pesquisas:

1) estruturadas: 24 entrevistas, sendo 12 entrevistas realizadas com a administração local e 12 junto a conselhos municipais (CME) e órgãos de representação e fiscalização dos municípios;

2) semiestruturadas: 25 entrevistas, junto a empresas (RH) e Órgãos Públicos contratantes, dez, com profissionais com deficiência, e três, com representantes de Conselhos e Órgãos de Defesa, Representação e Fiscalização dos municípios e Representante do Ministério do Trabalho da Região Metropolitana de Campinas e APAE; 
3) abertas: 05 entrevistas, sendo duas com representantes do Legislativo; duas com Diretoras do Fundo de Assistência e uma com a Secretaria de Direitos Humanos.

As entrevistas foram conduzidas no sentido de averiguar quais os elementos que tornam um município, na educação ou setor empresarial, mais inclusivos do que outros, e porque empresas isentas de contratação pela Lei de Cotas, espontaneamente empregam Pessoas com Deficiência. Como categoria analítica, procurou-se entender o processo de adesão local ao Programa Educação para Todos e Lei de Cotas, verificando a existência da prática sistemática das ações inclusivas no setor público e privado, à luz das Ações Afirmativas.

Quanto à instalação de Conselhos ou Órgãos de Defesa e Representação, observaram-se as iniciativas de Conselhos Municipais e Órgãos de Representação dos interesses das Pessoas com Deficiência, tendo em vista a inclusão educacional e profissional, à luz do processo de inclusão, divulgação e apoios conferidos pelo poder público e sociedade local:

1) Manifestação (aderência ou não para a elaboração dos instrumentos de pesquisas observando-se os pressupostos inclusivos);

2) Realização (positiva ou negativa);

3) Significação (propositiva e interpretativa).

Completa o levantamento de campo, as informações do Ministério do Trabalho, RAIS/CAGED; Ministério da Fazenda; Fundação SEADE e IBGE. As sínteses estão ilustradas nas Tabelas 3 e 4, organizadas por região, município e setor de atividade. Para cada uma das regiões selecionaram-se três cidades. A seguir, uma síntese das contratações divulgadas pela Superintendência Regional do Trabalho do Estado de São Paulo.

Tabela 05 - ESTADO DE SÃO PAULO: Contratações de Pessoas com Deficiência nas 04 Regiões Pesquisadas $e$ Potencial de Contratações

\begin{tabular}{c|c|c}
\hline $\begin{array}{c}\text { Regionais da Superintendência } \\
\text { Do Trabalho SP }\end{array}$ & $\begin{array}{c}\text { Contratados } \\
\mathbf{2 0 1 0}\end{array}$ & $\begin{array}{c}\text { otencial de Contratação } \\
\mathbf{2 0 1 0}\end{array}$ \\
\hline Santo André (Inclui S. Caetano Sul) & 2.979 & $7.676(38,80 \%)$ \\
\hline São Bernardo do Campo & 4.268 & $7.969(53,55 \%$ \\
\hline Campinas & 7.667 & $15.674(48,91 \%)$ \\
\hline Araçatuba (Inclui Alta Paulista) & 782 & $1.881(41,57 \%)$ \\
\hline Vale do Ribeira & Não publicado & Não publicado \\
\hline
\end{tabular}

Fonte: Superintendência Regional do Trabalho em São Paulo. Boletim de Análise n.6.Abril 2011

Não foram encontradas análises semelhantes nos exercícios posteriores que pudessem estabelecer comparativos na evolução do estoque de empregos. É de supor que regiões econômica e socialmente mais desenvolvidas tenham contratado profissionais com deficiência, proporcionalmente ao estoque efetivo da localidade. Todavia, observa-se que, essa premissa não se cumpre, conforme pode ser observado nas tabelas 03 e 04. 
Em todas as 4 Regiões Pesquisadas observou-se uma forte presença da APAE em programas de reabilitação, programas socioeducativos e emprego (Emprego Apoiado), que consiste no trabalho de intermediação entre a empresa e o profissional com deficiência, e acompanhamento até sua plena integração no ambiente laboral. A Alta Paulista e Registro guardam proporcionalidade entre número de habitantes e desenvolvimento econômico (baixo).

Na Região Metropolitana de Campinas (RMC) e ABC Paulista, com alto índice de desenvolvimento econômico e social, destacam-se os Municípios de Paulínia e São Caetano do Sul, detentores do Produto Interno Bruto (PIB), per capita, mais altos do Brasil, com resultados de inclusão profissional mais baixo comparativamente as demais cidades do entorno.

Tabela 06. ESTAdo DE SÃO PAUlO. Regiões Paulistas de Desenvolvimento Econômico BAIXO e de BAIXA Oferta de Emprego.

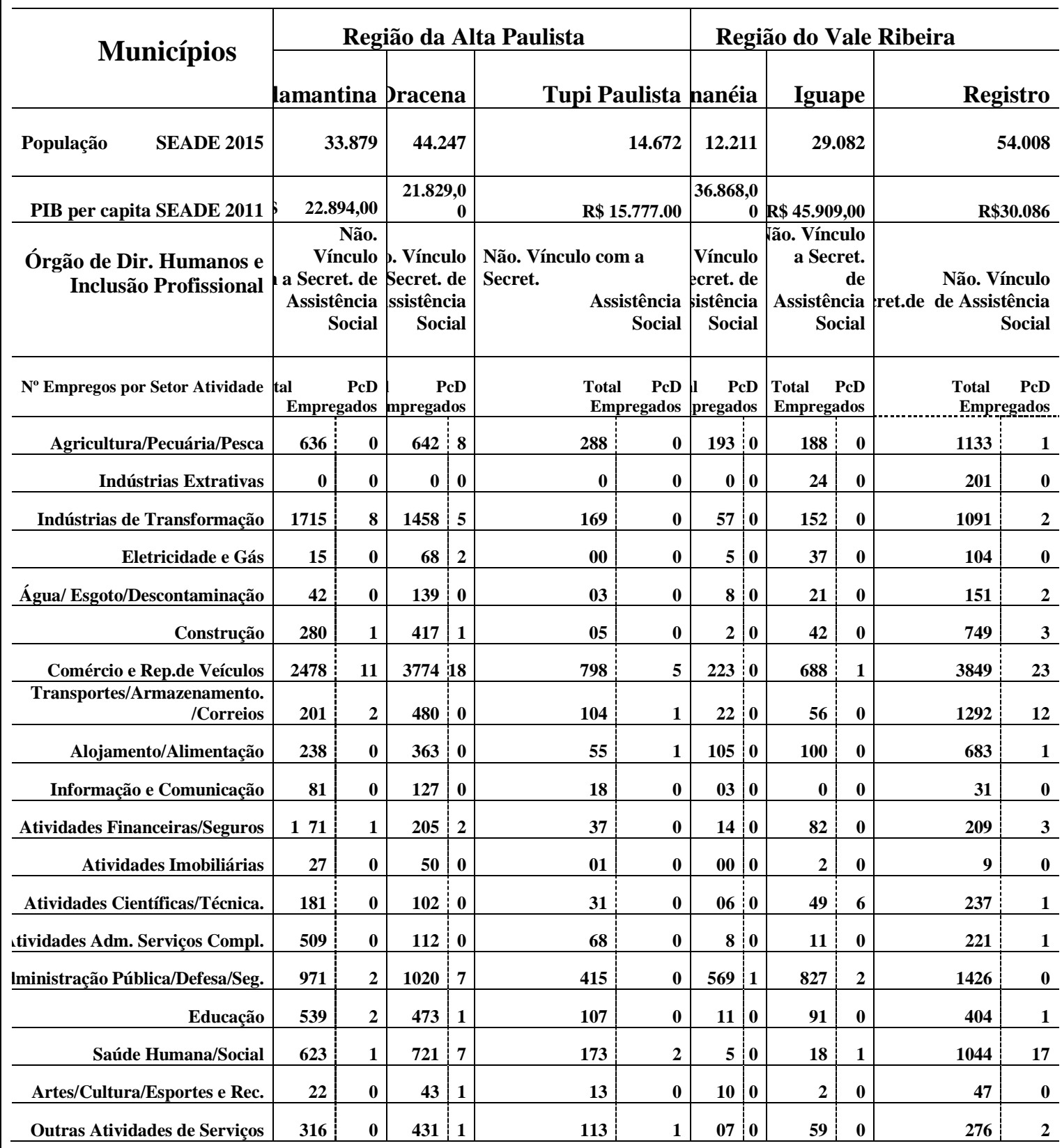




\begin{tabular}{|c|c|c|c|c|c|c|c|c|c|c|c|c|}
\hline Serviços Domésticos & 0 & 0 & 1 & $\mathbf{0}$ & 0 & $\mathbf{0}$ & $3: 0$ & 0 & 0 & $\mathbf{0}$ & 0 & \\
\hline ganismos Internacionais/Outros & $\mathbf{0}$ & $\mathbf{0}$ & 0 & 0 & 0 & $\mathbf{0}$ & $0: 0$ & & $\mathbf{0}$ & $\mathbf{0}$ & 0 & \\
\hline 2012: TOTAIS 5 & & 28 & & 52 & 2398 & 10 & \multicolumn{2}{|c|}{012449} & & 09 & 13157 & 69 \\
\hline 2014: Total de empregos & \multicolumn{2}{|c|}{9.312} & 11.27 & & \multicolumn{2}{|r|}{2.373} & \multicolumn{4}{|c|}{1.850} & \multicolumn{2}{|c|}{14.036} \\
\hline$(\%)$ & \multicolumn{2}{|c|}{$0,31 \%$} & 0,490 & & \multicolumn{2}{|c|}{$0.42 \%$} & $0,07 \%$ & \multicolumn{3}{|c|}{$0,36 \%$} & \multicolumn{2}{|r|}{$0.52 \%$} \\
\hline
\end{tabular}

Tabela elaborada pelas autoras. Fontes: RAIS/2012/FIPE-MODEN: Monitoramento da Inserção da Pessoa com Deficiência no mercado de Trabalho. Os números de profissionais com Deficiência empregados no exercício de 2014 permaneceram praticamente inalterados.

Tabela 07. ESTADO DE SÃO PAULO. Regiões Paulistas de ALTO Desenvolvimento e de ALTA Oferta de Emprego.

\begin{tabular}{|c|c|c|c|c|c|c|c|c|c|c|c|c|}
\hline \multirow{2}{*}{ Municípios } & \multicolumn{6}{|c|}{ Região Metropolitana de Campinas } & \multicolumn{6}{|c|}{ Região do Grande ABC Paulista } \\
\hline & \multicolumn{2}{|c|}{ Americana } & \multicolumn{2}{|c|}{ Paulínia } & \multicolumn{2}{|c|}{$\begin{array}{r}\text { Santa } \\
\text { Barbara } \\
\text { D'Oeste }\end{array}$} & \multicolumn{2}{|c|}{ Sto. André } & \multicolumn{2}{|c|}{$\begin{array}{l}\text { São } \\
\text { Bernardo } \\
\text { do Campo }\end{array}$} & \multicolumn{2}{|c|}{$\begin{array}{r}\text { São Caetano } \\
\text { do Sul }\end{array}$} \\
\hline População SEADE 2015 & \multicolumn{2}{|c|}{223.160} & \multicolumn{2}{|c|}{$\mathbf{9 5 . 0 3 3}$} & \multicolumn{2}{|c|}{189.233} & \multicolumn{2}{|c|}{710.210} & \multicolumn{2}{|c|}{816.925} & \multicolumn{2}{|c|}{158.024} \\
\hline IB per capita SEADE 2013 & \multicolumn{2}{|l|}{$\begin{array}{l}\mathrm{R} \$ \\
45.379,00\end{array}$} & \multicolumn{2}{|c|}{$\mathbf{R} \$ \quad 135.777,00$} & \multicolumn{2}{|c|}{$\mathbf{R} \$ 28.067,00$} & \multicolumn{2}{|c|}{$\mathbf{R} \$ 36.70,00$} & \multicolumn{2}{|c|}{$\mathbf{R} \$ 61.056,00$} & \multicolumn{2}{|c|}{$R \$ 102.018,00$} \\
\hline $\begin{array}{r}\text { Órgão de Dir. Humanos e } \\
\text { Inclusão Profissional }\end{array}$ & \multicolumn{2}{|c|}{\begin{tabular}{|c|} 
Sim. Lei Munic. \\
mprego Assistido
\end{tabular}} & \multicolumn{2}{|c|}{\begin{tabular}{|r|} 
rojeto Apresentado. \\
I./Vinculado à Prom. \\
Social
\end{tabular}} & \multicolumn{2}{|c|}{$\begin{array}{r}\text { Não. Casa } \\
\text { Io Trabalhador }\end{array}$} & \multicolumn{2}{|c|}{\begin{tabular}{|l|} 
Sim. Dir. Hum \\
e Secretaria de \\
Inclusão Social
\end{tabular}} & \multicolumn{2}{|c|}{$\begin{array}{r}\text { Atividades } \\
\text { Pontuais } \\
\text { CTR e SDSC }\end{array}$} & \multicolumn{2}{|c|}{$\begin{array}{r}\text { Sim. Inclusão } \\
\text { Social e Mobilidade } \\
\text { Reduzida }\end{array}$} \\
\hline Empregos por Setor Atividade & \multicolumn{2}{|c|}{$\begin{array}{|rr|}\text { Total } & \text { PcD } \\
\text { Empregados }\end{array}$} & \multicolumn{2}{|c|}{\begin{tabular}{|rr} 
Total & PcD \\
Empregados
\end{tabular}} & $\begin{array}{c}\text { Ctotal } \\
\text { Emprega }\end{array}$ & $\begin{array}{l}\text { PcD } \\
\text { ados }\end{array}$ & $\begin{array}{cc}\text { Total } & \mathbf{P} \\
\text { Emprega }\end{array}$ & IcD & $\begin{array}{c}\text { Total } \\
\text { Empreg }\end{array}$ & $\begin{array}{r}\text { PcD } \\
\text { zados } \\
\end{array}$ & $\begin{array}{l}\text { Total } \\
\text { Empreg }\end{array}$ & $\begin{array}{l}\text { PcD } \\
\text { gados }\end{array}$ \\
\hline Agricultura/Pecuária/Pesca & 54 & 1 & 214 & 1 & 214 & $\mathbf{0}$ & 09 & $\mathbf{0}$ & 210 & $\mathbf{0}$ & 8 & $\mathbf{0}$ \\
\hline Indústrias Extrativas & 38 & 1 & 111 & 1 & 111 & $\mathbf{0}$ & 4 & $\mathbf{0}$ & 87 & $\mathbf{0}$ & $\mathbf{0}$ & $\mathbf{0}$ \\
\hline Indústrias de Transformação & 26272 & 564 & 9996 & 564 & 9996 & 246 & 30654 & 206 & 20451 & 2404 & 25266 & 246 \\
\hline Eletricidade e Gás & 47 & 1 & 14 & 1 & 14 & 0 & 25 & 0 & 00 & 0 & 0 & $\mathbf{0}$ \\
\hline Água/ Esgoto/Descontaminação & 828 & 15 & 949 & 15 & 949 & 3 & 1555 & 17 & 565 & 22 & 29 & 3 \\
\hline Construção & 2992 & 27 & 7573 & 27 & 7573 & 3 & 8892 & 6 & 764 & 39 & 10784 & 3 \\
\hline Comércio e Rep.de Veículos & 16812 & 110 & 7159 & 110 & 7159 & 65 & 41402 & 44 & 8765 & 347 & 18250 & 65 \\
\hline insportes/Armazenamento/Correios & 3634 & 28 & 6472 & 28 & 6472 & 6 & 8506 & 39 & 1193 & 236 & 1042 & 6 \\
\hline Alojamento/Alimentação & 3210 & 12 & 2343 & 12 & 2343 & 12 & 8727 & 6 & 1367 & 48 & 5367 & 12 \\
\hline Informação e Comunicação & 3500 & 82 & 100 & 82 & 100 & $\mathbf{0}$ & 5297 & 1 & 265 & 22 & 2505 & 0 \\
\hline Atividades Financeiras/Seguros & 1275 & 24 & 287 & 24 & 287 & 9 & 3037 & 5 & 345 & 97 & 1694 & 9 \\
\hline Atividades Imobiliárias & 421 & 2 & 75 & 2 & 75 & $\mathbf{0}$ & 435 & $\mathbf{0}$ & 137 & $\mathbf{0}$ & 362 & $\mathbf{0}$ \\
\hline Atividades Científicas/Técnica. & 2012 & 3 & 1206 & 3 & 1206 & $\mathbf{0}$ & 4470 & 6 & 435 & 40 & 2431 & $\mathbf{0}$ \\
\hline Atividades Adm. Serviços Compl. & 5336 & 18 & 4532 & 18 & 4532 & 9 & 45708 & 20 & 3474 & 184 & 28497 & 9 \\
\hline Administração Pública, Defesa/Seg. & 6054 & 148 & 5042 & 148 & 5042 & 22 & 11242 & 40 & 4048 & 209 & 5609 & 22 \\
\hline Educação & 2078 & 17 & 761 & 17 & 761 & 8 & 10055 & 4 & 1092 & 148 & 3135 & 8 \\
\hline Saúde Humana/Social & 3125 & 39 & 1168 & 39 & 1168 & 9 & 18969 & 8 & 1126 & 84 & 3056 & 9 \\
\hline Artes/Cultura/Esportes/Recreação & 342 & 02 & 125 & 02 & 125 & 0 & 1174 & 1 & 136 & 4 & 545 & $\mathbf{0}$ \\
\hline Outras Atividades/Serviços & 1905 & 15 & 331 & 15 & 331 & 2 & 5189 & 3 & 472 & 153 & 1940 & 2 \\
\hline Serviços Domésticos & 2 & $\mathbf{0}$ & 0 & $\mathbf{0}$ & 0 & $\mathbf{0}$ & 1 & $\mathbf{0}$ & 4 & $\mathbf{0}$ & $\mathbf{0}$ & $\mathbf{0}$ \\
\hline Organismos Internacionais/Outros & 0 & $\mathbf{0}$ & 0 & $\mathbf{0}$ & & $\mathbf{0}$ & 0 & $\mathbf{0}$ & 0 & & 0 & $\mathbf{0}$ \\
\hline TOTAIS & 79928 & 1109 & 48457 & 425 & 44936 & 384 & 205352 & 894 & 77574 & 4037 & 119514 & 946 \\
\hline
\end{tabular}




\begin{tabular}{|c|c|c|c|c|c|c|c|}
\hline 2014: Total de empregos & 80.758 & 40.925 & & 48.332 & 215.750 & 287.065 & 112.826 \\
\hline$(\%)$ & $1,38 \%$ & & $0,89 \%$ & $0.86 \%$ & $0,92 \%$ & $1,45 \%$ & $0.79 \%$ \\
\hline
\end{tabular}

Tabela elaborada pelas autoras. Fontes: SEADE/RAIS/2012/FIPE-MODEN: Monitoramento da Inserção da Pessoa com Deficiência no mercado de Trabalho. Os números de profissionais com Deficiência empregados no exercício de 2014, permaneceram praticamente inalterados.

A justaposição de dados das regiões de Registro e do ABC Paulista em 2012 revelam (repetindo-se analogamente em 2014) que em Registro há 0,52\% de PcDs em seu quadro de trabalhadores efetivos, e, em Iguape, 0,36\%. No ABC Paulista aparecem Santo André, com 0,92\%, e São Caetano do Sul, com 0,79\%. Este último, embora detenha o mais alto PIB per capita dos três municípios analisados ( $\mathrm{R} \$ 102.018,00)$, apresenta um percentual de contratação de Pessoas com Deficiência de apenas 0,79\%, inferior aos municípios limítrofes.

O município mais inclusivo, São Bernardo do Campo, tem um PIB per capita de $\mathrm{R}$ \$ 61.056,00 e um percentual de empregos de Pessoas com Deficiência de 1,45\%. Assim, o Município de Americana, com um PIB per capita de R\$ 45.379,00, comparativamente ao percentual relativo a profissionais com deficiência incluídos $(1,38 \%)$ é o que apresenta os melhores resultados, dentre os estudados. A análise dos estoques de empregos confrontados com a potencialidade de inserções no mercado de trabalho, nas regiões pesquisadas, esclarece que as regiões economicamente mais desenvolvidas realizam o mesmo percentual de inserção da região menos desenvolvida (Alta Paulista).

Nos estudos regionais, os municípios pesquisados da Alta Paulista e do Vale do Ribeira, mesmo com baixa oferta de emprego e empresas de pequeno porte, apresentam um percentual médio de empregos de Pessoas com Deficiência de $0,42 \%$, exceção feita de Cananeia, que oferece somente um posto de trabalho, mesmo acusando o total de 569 pessoas trabalhando no setor público.

A Instrução Normativa 98/2012 foi emitida após o Ministério do Trabalho ter constatado o declínio das contratações, entre 2008 a 2012, o que o levou a fixar procedimentos de fiscalização sobre o cumprimento patronal de normas destinadas à inclusão no trabalho das Pessoas com Deficiência e dos Beneficiários da Previdência Social reabilitados. Tomando por base a Instrução, estabeleceu-se um roteiro de entrevistas, com três dos atores mais envolvidos na inclusão profissional: Organizações, Empregados e Ministério do Trabalho. 


\section{Quadro 01: IN 098/2012. Ação das Empresas; Atos da Gerência Regional MTE; Percepção dos Profissionais com Deficiência.}

\begin{tabular}{|c|c|c|c|}
\hline $\begin{array}{r}\text { Instrução Normativa } \\
098 / 2012\end{array}$ & $\begin{array}{l}\text { Empresas } \\
\text { Contratantes }\end{array}$ & $\begin{array}{r}\text { Ministério do Trabalho: } \\
\text { RMC }\end{array}$ & Profissionais c Deficiêr \\
\hline 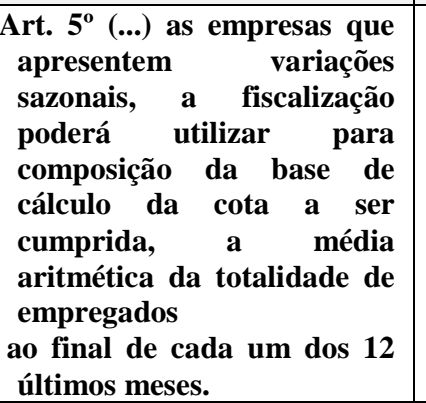 & $\begin{array}{l}\text { As Empresas foram } \\
\text { autuadas em função do } \\
\text { não cumprimento desse } \\
\text { Inciso. Antes de } 2004 \text { as } \\
\text { contratações eram baixas } \\
\text { por falta de informações e } \\
\text { interesse das PcD. Nesse } \\
\text { ano e nos seguintes, } \\
\text { muitas multas e TACs } \\
\text { foram assinados. }\end{array}$ & $\begin{array}{lr}\text { A partir de 2004, as ações } \\
\text { do MTE roram } \\
\text { intensificadas. } \\
\text { um núcleo de combate à } \\
\text { discriminação } \\
\text { acompanhamento. Fom } \\
\text { realizadas Foram } \\
\text { mensais para sedimentar o } \\
\text { trabalho do núcleo. As } \\
\text { autuações foram mais } \\
\text { frequentes até } 2010\end{array}$ & $\begin{array}{l}\text { Nas pesquisas de campo } \\
\text { os profissionais com } \\
\text { deficiência ran não } \\
\text { souberam comentar o } \\
\text { artigo. }\end{array}$ \\
\hline 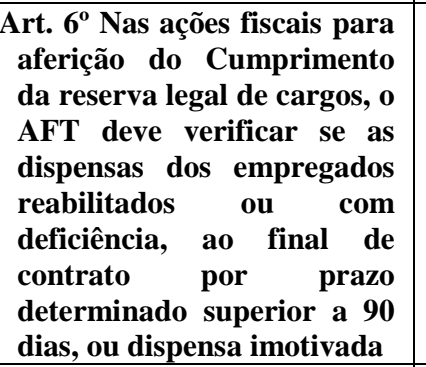 & $\begin{array}{l}\text { As empresas obedecem } \\
\text { essa determinação, nãd } \\
\text { dispensando funcionári } \\
\text { que retorna após o períod } \\
\text { de afastamento por } 90 \text { dias } \\
\text { O que ocorre muito é a nã } \\
\text { adaptação do mesmo en } \\
\text { outras áreas e funções. }\end{array}$ & 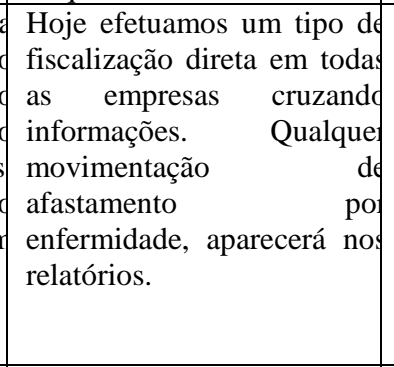 & $\begin{array}{l}\text { Nem sempre isso ocorre } \\
\text { As dispensas ocorrem apó } \\
\text { um ano do período do } \\
\text { afastamento, } \\
\text { atendimento do prazo } \\
\text { Legal. }\end{array}$ \\
\hline 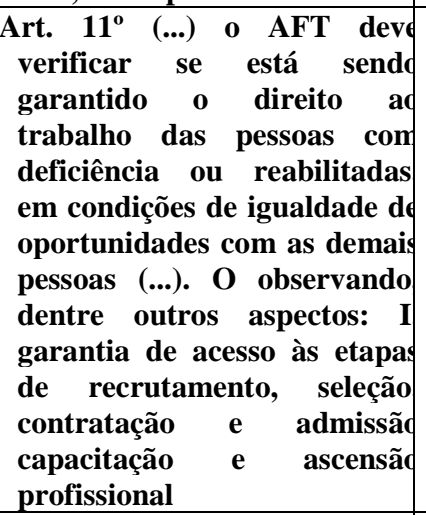 & $\begin{array}{l}\text { Recrutamento difícil, se do } \\
\text { para funções específicas } \\
\text { pré-determinadas, onde } \\
\text { empresa possu } \\
\text { acessibilidade e podd } \\
\text { proporcionar condições do } \\
\text { trabalho adequadas às } \\
\text { Pessoas com Deficiência } \\
\text { Os cargos mais demandado } \\
\text { são de auxiliares } \\
\text { assistentes. }\end{array}$ & $\begin{array}{l}\text { Tem coisas que não dã } \\
\text { para captar. Todavia } \\
\text { registramos os históricos de } \\
\text { contratação, salários } \\
\text { categorias salariais. Já } \\
\text { aconteceu que ume } \\
\text { determinada empresa criou } \\
\text { uma função "auxiliar", en } \\
\text { que se mantinha um saláric } \\
\text { mais baixo, categoria que } \\
\text { englobava todas as Pessoas } \\
\text { com Deficiência. }\end{array}$ & 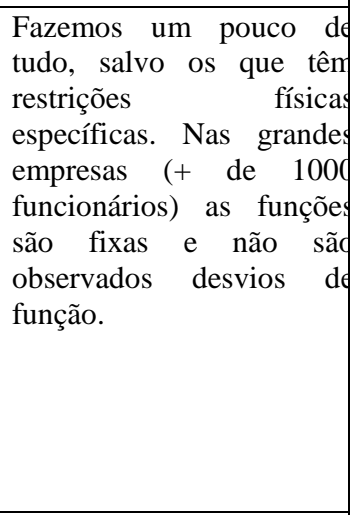 \\
\hline $\begin{array}{|lr|}\text { II. distribuição, pela empresa } \\
\text { dos empregados con } \\
\text { deficiência ou reabilitados nos } \\
\text { diversos cargos, funções } \\
\text { postos de trabalho, setores } \\
\text { estabelecimentos, } \\
\text { preferencialmente de forma } \\
\text { proporcional, tendo com } \\
\text { parâmetro as reais } \\
\text { potencialidades individuais } \\
\text { as habilidades requeridas (...) }\end{array}$ & $\begin{array}{l}\text { Os funcionários sã } \\
\text { contratados em função das } \\
\text { vagas disponibilizadas, en } \\
\text { sua maioria, operacionais } \\
\text { auxiliares, assistentes at } \\
\text { adquirir alguma formação } \\
\text { Esse é ainda um trabalh } \\
\text { em construção, social } \\
\text { funcional. }\end{array}$ & $\begin{array}{l}\text { Tem empresas com bon } \\
\text { projetos de acessibilidade } \\
\text { mas, via de regra, há uma } \\
\text { adaptação dos ambientes de } \\
\text { acordo com as necessidades } \\
\text { Estamos atentos } \\
\text { aglomeração de Pessoas } \\
\text { com Deficiência num únicc } \\
\text { espaço. }\end{array}$ & $\begin{array}{l}\text { São contratados para o } \\
\text { setores que já tên } \\
\text { acessibilidade física e con } \\
\text { ambientes adaptados } \\
\text { Como relatado, as posiçõe } \\
\text { oferecidas são } \\
\text { subemprego, e nã } \\
\text { condizentes com o que } \\
\text { profissional tem a oferecer }\end{array}$ \\
\hline V. remuneração equitativa; & \begin{tabular}{lrr} 
Todas os & \multicolumn{2}{c|}{ entrevistado } \\
atendem & a & esso \\
determinação. Não existen \\
diferenças salariais. & As \\
pessoas contratadas, & sen \\
exceção $\quad$ entram & ñ \\
classificação salarial & do \\
iniciantes na carreira.
\end{tabular} & $\begin{array}{l}\text { Sim, as remunerações sã } \\
\text { equivalentes, ressalvando } \\
\text { caso acima citado da criaçãa } \\
\text { de uma função "auxiliar". Jâ } \\
\text { autuamos empresa, depois } \\
\text { de orientá-la a observar } \\
\text { piso da categoria. }\end{array}$ & $\begin{array}{l}\text { Sim são iguais, mas } \\
\text { condicionadas às horas dd } \\
\text { trabalho, e nesse caso os } \\
\text { benefícios (férias) sãd } \\
\text { proporcionais à jornada, } \\
\text { na faixa salarial do } \\
\text { iniciantes. }\end{array}$ \\
\hline VI. acessibilidade ampla; & $\begin{array}{l}\text { A acessibilidade é, via de } \\
\text { regra, parcial. }\end{array}$ & $\begin{array}{l}\text { Não posso afirmar com } \\
\text { segu-rança, pois teria de } \\
\text { visitar todas as empresas } \\
\text { Quando um auditor vai } \\
\text { empresa, pedimos verifical }\end{array}$ & $\begin{array}{l}\text { Nos espaços de trabalho o } \\
\text { Bancos são os que mai } \\
\text { atendem o } \\
\text { acessibilidade, pois ele } \\
\text { precisam atender o públice }\end{array}$ \\
\hline
\end{tabular}




\begin{tabular}{|c|c|c|c|}
\hline & & esse item. & geral. \\
\hline $\begin{array}{l}\text { VII. condições de saúde e } \\
\text { segurança adaptadas às } \\
\text { necessidades } \\
\text { empregados. }\end{array}$ & $\begin{array}{l}\text { Na medida do possível, } \\
\text { procuram congregar } \\
\text { todos os profissionais } \\
\text { com defi-ciência em } \\
\text { setores acessí-veis, que } \\
\text { proporcionam conforto } \\
\text { e segurança. }\end{array}$ & $\begin{array}{l}\text { Essa é uma área } \\
\text { direcionada a nossa } \\
\text { médica e auditora, que } \\
\text { faz palestras para tratar } \\
\text { dessa questão, assim } \\
\text { como os procedimentos } \\
\text { adotados. }\end{array}$ & $\begin{array}{lr}\text { Sim. As } & \text { grandes } \\
\text { empresas } & \text { observam } \\
\text { esse item. } & \end{array}$ \\
\hline $\begin{array}{l}\text { Art. } 13^{\circ} \text { Caberá ao AFT } \\
\text { verificar se no processo de } \\
\text { Inclusão da } \\
\text { PcD ou reabilitada, a } \\
\text { empresa promoveu as } \\
\text { modificações dos postos de } \\
\text { trabalho, da or-ganização } \\
\text { do trabalho e con-dições } \\
\text { ambientais, em confor- } \\
\text { midade c/ as necessidades } \\
\text { do trabalhador. }\end{array}$ & $\begin{array}{l}\text { As modificações } \\
\text { ocorreram nos espaços } \\
\text { que tem Pessoas com } \\
\text { Deficiência } \\
\text { contratadas. Itens como } \\
\text { "sanitários" sempre são } \\
\text { adaptados. }\end{array}$ & $\begin{array}{lrr}\text { Esse é } & \text { um } & \text { item } \\
\text { delicado. É necessário } \\
\text { estar in loco para } \\
\text { analisar cargos } & \text { ou } \\
\text { funções ocupadas por } \\
\text { Pessoas } & \text { com } \\
\text { Deficiência e analisar } \\
\text { se as condições, } \\
\text { equipamentos } \\
\text { material de apoio são } \\
\text { adequados. }\end{array}$ & $\begin{array}{l}\text { Não perguntado sobre } \\
\text { essa questão }\end{array}$ \\
\hline $\begin{array}{l}\text { Parag. Único. O AFT deve } \\
\text { verficar a adaptação das } \\
\text { condições de trabalho às } \\
\text { características } \\
\text { psicofisiológicas dos } \\
\text { trabalhadores, de modo a } \\
\text { pro-porcionar o máximo } \\
\text { conforto, segurança e } \\
\text { desempenho. }\end{array}$ & $\begin{array}{l}\text { Foram relatados } \\
\text { de mobbing. } \\
\text { funcionários } \\
\text { contratados, iniciantes } \\
\text { no emprego, são } \\
\text { sensíveis } \\
\text { brincadeiras às } \\
\text { colegas pois ainda são } \\
\text { novos no mundo } \\
\text { empresarial. }\end{array}$ & $\begin{array}{l}\text { Casos de assédio moral, } \\
\text { o que inclui questões } \\
\text { psicológicas, } \\
\text { fisiológicas, segurança, } \\
\text { normalmente rão } \\
\text { direcionados r ao } \\
\text { Ministério Público. }\end{array}$ & $\begin{array}{l}\text { Sim. Temos casos } \\
\text { discriminação } \\
\text { profissional e social e } \\
\text { com alguns "apelidos" } \\
\text { ou brincadeiras que } \\
\text { desagradam. }\end{array}$ \\
\hline 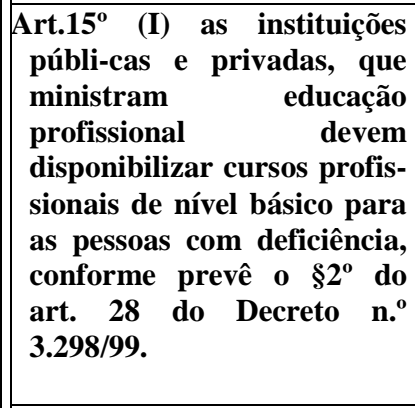 & $\begin{array}{l}\text { Atendimento parcial. } \\
\text { Existe o treinamento na } \\
\text { função. Se a função } \\
\text { para qual a pessoa } \\
\text { selecionada não possuir } \\
\text { qualificação, orienta-se } \\
\text { para fazê-lo. Todavia } \\
\text { esses cur-sos são pagos } \\
\text { e nem todos têm } \\
\text { condições econômicas. }\end{array}$ & $\begin{array}{l}\text { O Sistema S deveria } \\
\text { disponibilizar } \\
\text { número de vagas para } \\
\text { atender às PcD. Todavia, } \\
\text { independentemente do } \\
\text { sistema } S \text {, tem empresas } \\
\text { na região com projetos } \\
\text { de qualificação } \\
\text { profissional dignos de } \\
\text { nota. }\end{array}$ & $\begin{array}{l}\text { As empresas orientam } \\
\text { (grandes empresas) e } \\
\text { sugerem cursos de } \\
\text { qualificação r na } \\
\text { companhia ou fora. } \\
\text { Alguns dos cursos } \\
\text { custeados } \\
\text { empresa. }\end{array}$ \\
\hline $\begin{array}{l}\text { (III) Promoção } \\
\text { campanhas de internas de } \\
\text { valorização da } \\
\text { diversidade e de combate à } \\
\text { discriminação e ao assédio. }\end{array}$ & $\begin{array}{lr}\text { Quando isso acontece, } \\
\text { recorremos } \\
\text { consultorias } \\
\text { especializadas } \\
\text { palestras } \\
\text { esclarecimentos. }\end{array}$ & $\begin{array}{l}\text { Quando } r \text { observamos } \\
\text { assédio, encaminhamos } \\
\text { ao Ministério Público. }\end{array}$ & $\begin{array}{l}\text { As grandes empresas } \\
\text { fixam cartazes e } \\
\text { treinam os gestores de } \\
\text { áreas. É comum } \\
\text { "mobbing" } \\
\text { colegas. entre }\end{array}$ \\
\hline
\end{tabular}

Fonte: Quadro elaborado pelas autoras a partir das entrevistas realizadas.

A Secretaria da Gerência Regional de Campinas informou que o programa de Inclusão de Pessoas com Deficiência registra o total de 48 empresas, com 3.669 profissionais com deficiência contratados, representando, a partir da edição da norma, 48,30\% do total de contratações (7.604). Essas cifras representam um universo de apenas $8 \%$ de empresas fiscalizadas (638). A média das contratações, a partir de 2004, passou para 320. Nos anos anteriores, de 2000 a 2003, registra-se uma média de apenas 72 contratações anuais. 
Observa-se nas entrevistas acima, partindo dos aspectos legais, a distância de percepção do Profissional com Deficiência e as políticas adotadas pelas empresas. As divergências encontram-se também no campo da educação profissional, com críticas ao Sistema S.

O que é comum, e perceptível nas três categorias de entrevistados, é com relação aos salários equitativos, muito embora algumas empresas tenham criado algumas categorias de "auxiliares" para a contratação de profissionais com deficiência. Pontua-se também a ocorrência de assédio moral, conforme relatado.

\section{Percepções dos Diversos Atores Sociais sobre a Inclusão}

As percepções e conhecimentos do mercado de trabalho e educação dos profissionais com deficiência, categorizados por escolaridade apresentada, fornecem uma abordagem sobre as políticas públicas de inclusão que escapa aos balanços oficiais, podendo ser assim sumariadas:

1. Os Profissionais com Curso Superior Completo consideram que os programas elaborados constituem um avanço, dando a oportunidade à $\mathrm{PcD}$ (Pessoa com Deficiência) de resgatar a sua identidade. Consideram também que, ou por obrigação ou conscientização, o fato é que a PcD está hoje no mercado de trabalho. No entanto, notam que as ofertas de trabalho são caracterizadas como subemprego: funções operacionais ou auxiliares.

2. O preenchimento das vagas e o atendimento do setor de Recursos Humanos caracterizam-se pela falta de oportunidades de contato e exposição dos conhecimentos e habilidades da PcD. O sistema de recrutamento por sites especializados em busca e oferta de trabalho são funis eliminatórios, baseados nos pressupostos da não qualificação ou não adaptabilidade de uma determinada modalidade de deficiência.

3. As críticas também são direcionadas aos gestores que veem na deficiência um fator impeditivo ao acesso e à promoção. Os entrevistados concordam com o fato de que os critérios de aprovação ou rejeição independem da capacidade da Pessoa com Deficiência, mas daquilo que os gestores podem pressupor como elementos impeditivos para a boa execução da tarefa. O problema é ilustrado por um engenheiro que enviou o seu curriculum, candidatando-se a uma vaga e não teve nenhuma resposta. Somente conseguiu uma entrevista, na mesma empresa, pela intermediação do Emprego Apoiado da APAE.

4. Os profissionais com o ensino fundamental completo e o ensino médio (completo ou não) consideram que a progressão continuada do ensino fundamental trouxe muitos problemas, dificultando o acesso ao ensino profissionalizante. Os cursos de qualificação profissional do SESI, SESC e SENAI deveriam oferecer cursos gratuitos às Pessoas com Deficiência, sem limitação do número de vagas ofertadas, e maior abertura quanto aos requisitos qualificatórios. Também consideram a educação formal repetitiva e monótona.

5. Os depoimentos de profissionais reabilitados veem a falta de adequação do ambiente físico da empresa como uma das dificuldades para a sua permanência no emprego e para que possam assumir novas tarefas. Tal fato é gerador de desestímulo profissional, pelas novas condições de trabalho, levando ao rompimento do vínculo empregatício 
(Percepção compartilhada pelo MTE, conforme boletins de Inserção das Pessoas com Deficiência).

6. Quanto ao assédio moral no trabalho, as entrevistas deixam entrever a existência de um limiar tênue entre "sensibilidade excessiva" (termo definido por profissionais com ou sem deficiência) e assédio moral. A forma de expor o caso reveste-se da maior importância, uma vez que dela podem se originar problemas legais para a empresa. A sensibilidade pode ser analisada por várias vertentes. Uma delas, aponta para os próprios colegas de trabalho, que, quando pressionados por metas a cumprir, tendem a responder aos colegas com deficiências de forma não apropriada.

7. Por sua vez, as entrevistas realizadas com representantes de empresas de consultoria, assessoria, ONGs e outras instituições sem fins lucrativos sublinham as dificuldades que encontraram para o recrutamento e seleção de profissionais com deficiência, providos de perfis adequados para o preenchimento das vagas oferecidas. A esse respeito ressalta-se que Campinas dispõe de empresas e organizações especializadas na intermediação de mão de obra, dentre as quais figura "O Emprego Apoiado" (APAE), que vem recebendo forte adesão das empresas locais.

8. No Município de Americana, a APAE (2014) vem atuando fortemente no mesmo projeto, contando com 27 empresas de grande porte, que aderiram ao programa emprego apoiado, e com cerca de 220 Pessoas com Deficiência contratadas nessa modalidade. De acordo com o depoimento da diretoria da APAE, a PcD que chega para atendimento de reabilitação, disposta a ingressar no mercado de trabalho, aguarda uma vaga ou vai para um programa inicial de preparação técnica para as funções a serem exercidas.

9. Quando há solicitação empresarial, a pessoa com perfil mais próximo à vaga é selecionada e se efetua o seu encaminhamento para a empresa. A cada 15 dias, a empregadora libera o contratado para ir até a APAE, a fim de cumprir uma rotina de monitoramento e orientação. Quando há algum problema com o contratado (por exemplo, o excesso de faltas sem os competentes atestados médicos, a negligência no trabalho, e demais fatos dessa natureza), a empresa aciona a APAE, para que atue junto ao colaborador, tentando dirimir as falhas apresentadas. Tal fato evidencia a falta de preparo de algumas organizações para lidar com as diferenças.

10. As entrevistas com as empresas contratantes trazem à tona que o programa de inclusão se iniciou após 2004, quando da intensificação da fiscalização do Ministério Público do Trabalho, quando ocorreram assinaturas de TAC (Termo de Ajuste de Conduta). Os discursos dos coordenadores de RH são semelhantes, quer na dimensão tática, quer nos pressupostos para a implantação das políticas delineadas pela organização.

11. Algumas empresas declararam que as políticas organizacionais, que tratam da inclusão, ainda não foram totalmente absorvidas pelos gestores, sob a alegação de falta de mão de obra não qualificada, falta de planos para retenção ou de cargos e salários para PcD. O ambiente de trabalho destinado às Pessoas com Deficiência, de acordo com as entrevistas, não se apresenta como um agrupamento setorial, mas como um espaço de otimização da acessibilidade já existente. Quanto às pressões apontadas, são aqueles inerentes a toda empresa: cumprimento de prazos e metas são de responsabilidade de todos, porém, com menores exigências para as PcDs.

12. As respostas sobre os motivos que levam pequenas empresas a contratar Pessoas com Deficiência esclarecem que essa atitude é intrínseca ao ser humano. Um dos 
empresários entrevistados (do setor têxtil) descreve outros tipos de inclusão, afirmando ser essa uma prática rotineira de sua gestão. Pessoas com Deficiência têm sido contratadas por sua empresa desde 1975; em sua maioria, surdos-mudos, apesar de ninguém na fábrica conhecer a língua dos sinais.

13. De acordo com o entrevistado, mesmo com alguns obstáculos iniciais de integração, a entrada de PcDs constituiu um aprendizado para todos, tendo esses profissionais contribuído para o desenvolvimento de uma nova cultura de trabalho. A contratação, não se dava somente nessa modalidade de deficiência, mas em todas aquelas que pudessem ser compatíveis com o ramo de sua atividade.

14. Os gestores do Executivo de um dos municípios da Região Metropolitana de Campinas, por sua vez, declaram ter cumprido a lei quanto à reserva de cotas nos concursos públicos (uma lei municipal destina $10 \%$ das vagas públicas às Pessoas com Deficiência). O município mantém uma parceria com a APAE, e muitas vezes, na primeira fase do treinamento para ingresso no mercado de trabalho, os futuros profissionais estagiam em órgãos da Prefeitura.

15. A Câmara Municipal do Município de Americana (Ver. Celso Zoppi) considera que muitas empresas não cumprem a Lei, mas que vem ocorrendo uma mudança na cultura organizacional e na sociedade, de forma geral. A posição que defende é a da contratação de Pessoas com Deficiência também nas empresas com até 100 funcionários, pela facilidade de acesso que essas pessoas têm diretamente com os empresários, muitas vezes mais sensíveis a essa questão.

16. Um outro aspecto mencionado, que segundo os entrevistados, precisa ser estudado com cuidado, é a terceirização: quem é responsável pelo contratação e a quem cabe a responsabilidade pelo atendimento das cotas: à contratante ou à contratada? Existem muitos olhares quando o assunto é a contratação de Pessoas com Deficiência. A Deputada Federal Mara Gabrilli dispõe de uma equipe, que viaja pelo Estado procurando orientar a contratação, o que é feito por meio de palestras. Vários projetos voltados à Pessoa com Deficiência, não somente na área do emprego, mas também nos esportes e saúde ocupacional e atletismo para-olímpico, foram implementados.

17. Um fator de importância mencionado é relativo à ação da Câmara dos Vereadores: as medidas adotadas para a inclusão de PcD nos planos de desenvolvimento humano e promoção do emprego, de modo geral, limitaram-se a apresentar cifras e textos legais sobre as medidas de inclusão adotadas, sempre consonantes com os demais poderes.

Todos os entrevistados se referiram à importância da atuação de conselhos específicos para tratar da inclusão de PcDs no mercado de trabalho. Os membros participantes dos conselhos municipais provêm de várias entidades. O Conselho de Desenvolvimento Humano tem poderes deliberativos e a missão de garantir o desenvolvimento pleno, a autonomia e a participação efetiva de todos os membros da comunidade. Encontra-selotado na Secretaria de Assistência Social, via de regra em todos municípios, para ficar mais próximo do atendimento da população e da ação operacional. Uma proposta, que já existe na Administração Local (Americana), é a de juntar todos os Conselhos num mesmo espaço ou em locais próximos.

O que se observou nos últimos estudos de campo é uma falta de integração com os demais Conselhos. Falta um plano integrador de ação. A participação social é boa, mas o grau de poder decisório dos interessados é muito baixo. Não se pode falar em inclusão profissional, se não se falar de capacitação formal (educacional) e funcional. 


\section{Considerações Finais}

Este trabalho analisou os limites do acatamento da Lei de Cotas, com o objetivo de verificar as confluências entre a linguagem e inclusão, como tributárias de políticas públicas e da mobilização da sociedade como um todo. Uma das conclusões substantivas a que se chega é que a formação educacional, como exigência de base para o ingresso de pessoas no mercado de trabalho, não atende devidamente as Pessoas com Deficiência, dos mais baixos estratos sociais.

A inclusão da PcD é relativamente nova na História, uma vez que a sociedade relegou à obscuridade e ao silêncio cultural os seus membros que apresentassem desvios do modelo de normalidade, física ou mental, estabelecido pela tábua social de valores. No mundo todo, essa posição vem sendo corrigida, e os excluídos, por apresentarem necessidades especiais, cerram fileiras com outras minorias, rumo à cidadania, a todos assegurada por tratados e convenções nacionais e internacionais.

No Brasil, a Constituição de 1988, junto a outros diplomas legais, estatuíram os direitos de cidadão das Pessoas com Deficiência. Na prática, a inclusão vigora apenas na letra da lei, ainda com reflexos insuficientes na prática social. A inclusão educacional, mais operante no corpus legal, deve ser completada pela inclusão dos milhões de brasileiros, com graus diversos de deficiências, em natureza e gravidade, no mercado de trabalho. Apesar de ter sido ignorada por muito tempo, a inclusão no Brasil vem-se ampliando, ainda que lentamente. A cultura social e profissional começa a sair dos paradigmas que vê a Pessoa com Deficiência como um doente a ser atendido pela rede médico-hospitalar e por políticas assistencialistas, adotando paradigmas relacionados à igualdade de oportunidades, no viés da inclusão. Observa-se, pelas entrevistas, que essa mudança de paradigmas incorpora não somente direitos, mas também valores humanos por aqueles que a praticam.

Constatou-se que vários elementos estão diretamente vinculados e são determinantes ou não do sucesso de uma política regional e local de inclusão. Esses aspectos se interligam e compõem um caleidoscópio: cultural, social, educacional, político e profissional. Este estudo procurou apreender o máximo possível dessa realidade, materializada nas vidas de homens e mulheres, mas também nas instituições que formulam políticas públicas de inserção de indivíduos com necessidades especiais, na escola e na esfera produtiva.

Os dados obtidos são evidenciadores do papel do trabalho na promoção da autoestima e da realização pessoal, contribuindo para a sua estabilização física e emocional. A ausência de trabalho traduz-se no agravamento das carências das Pessoas com Deficiência, tornando-as ainda mais vulneráveis a uma realidade social injusta.

A coexistência da obrigatoriedade da contratação e as modalidades estáveis de pensamento e cultura implicam a forma de se relacionar com esses profissionais no ambiente de trabalho. Enquanto esse processo decorrer tão somente do caráter obrigatório da lei, a cultura de inclusão tende a distanciar-se de seus objetivos básicos, favorecendo situações de mobbing dentro das organizações.

Ao se levar em conta que o pressuposto da inserção dos indivíduos com deficiência no setor laboral implica que o mesmo ocorra em igualdade de condições com os demais trabalhadores - constatou-se que os objetivos da lei não se confirmaram 
em sua plenitude. Como exemplo, citam-se as contratações condicionadas às estruturas físicas da empresa, adicionadas apenas a algumas modificações consideradas mais urgentes. As ações de adequações são realizadas por etapas e nos setores que mais têm condições de receber profissionais com deficiência. Constata-se, ademais, que as vagas oferecidas são de baixa qualificação e nem sempre condizem com a escolaridade do candidato.

As contradições também aparecem nos municípios de mais alto desenvolvimento econômico do Brasil, permitindo a conjectura de que, se não houver interesse político na edição de Ações Afirmativa e incentiva à inclusão educacional e laboral, as premissas de direito ao trabalho não se concretizam.

O mapeamento da situação brasileira em recortes por Grandes Regiões e Categorias Populacionais e por Municípios assumiu o papel de uma verdadeira bússola, orientadora das pesquisas de campo. - em que pese a falta de disponibilização dos micros dados por parte dos Órgãos, Fundações e Instituições Públicas. Os resultados das pesquisas exploratórias e qualitativas, numa interação das vozes, indicaram a necessidade de ajustes nas políticas de inclusão profissional em âmbito municipal, adequando-as a sua temporalidade, conforme os pressupostos e preceitos que pregam os pressupostos expressos em Lei e em Ações Afirmativas.

A reflexão sobre a articulação entre educação apropriada e mercado de trabalho permite considerar a retroalimentação mútua entre desenvolvimento pleno e condições dignas de subsistência para Pessoas com Deficiência. Da formulação das macro políticas públicas às dificuldades de articulação municipal e estadual, os resultados desta análise confirmaram que a conexão entre os diferentes órgãos da administração pública é essencial para que a inclusão profissional de grupos vulneráveis ocorra em bases mais efetivas e chegue a melhores resultados.

Este estudo, de caráter interdisciplinar, buscou contribuir para a compreensão de um dos problemas mais candentes da atualidade: como os direitos humanos e de cidadania podem ser estendidos a pessoas pertencentes a grupos vulneráveis em nossa realidade social.

Os resultados apontam para a necessidade de diversas reformulações em procedimentos organizacionais, como também para a adequação e aperfeiçoamento da legislação às práticas sociais vigentes. A título de exemplo, sugere-se a adoção de um sistema misto de cotas contribuição, tal como acontece em países como o Japão, onde os fundos são recolhidos e administrados por uma empresa paraestatal, dirigida por Pessoas com Deficiência, sob a fiscalização de profissionais do Governo. Os recursos arrecadados destinam-se a fornecer bônus financeiros às empresas contratantes para desenvolver projetos de acessibilidade. Tal fundo, além de ser redistributivo, poderia alavancar, pelos incentivos propostos, as contratações de Pessoas com Deficiência por pequenas e médias empresas. Seria um modelo redistributivo a exemplo do que foi adotado pela via do FUNDEB na educação. Toma-se aqui o exemplo do Município de Paulínia e São Caetano do Sul: os mais altos PIB's per Capita do Brasil e um índice de inclusão baixo. Se as características das indústrias locais podem dificultar a inclusão, por que não contribuir para um Fundo Nacional para essa finalidade?

A pesquisa realizada também deixou claro que o problema da inclusão de Pessoas com Deficiência, na educação e no mercado de trabalho atinge a todos os membros da sociedade. Assim, deve ser vista como um dado da racionalidade 
administrativa, que aconselha o aproveitamento máximo da potencialidade de todos os cidadãos, tendo em vista alcançar um nível adequado de desenvolvimento coletivo e bem-estar social para a nação. Recomenda-se a continuidade de estudos futuros para monitoramento da inclusão como um alerta social no cumprimento daquilo que deveria ser natural: iguais no direito considerando as desigualdades peculiares de cada ser.

\section{REFERÊNCIAS}

AMORIM, W. A. C. et al. Trabalho Decente, Ética e Liberdade. Revista de Ciências Humanas, vol. 44, n 2. Florianópolis: 2010.

BESTER, G. M. A Constitucionalidade da alma como um bem jurídico a proteger e o direito à saúde psíquica nas relações laborais. In: IV Colóquio de Psicopatologia e Saúde pública: estratégias Participativas na Educação, no Trabalho e na Justiça. São Paulo: USP, 2009.

BRASIL. Presidência da República. Lei 3.146 de 2015.

CALLEGARI, C. R. Radicalizar o pacto pelas crianças do Brasil. In: Folha de São Paulo: Tendências e Debates. Publicado em 03.06.2015.

DALLARI, D. de A. Elementos de teoria geral do Estado. $32^{\text {a }}$ ed. São Paulo: Saraiva, 2013.

DEJOURS, C. Da psicopatologia à psicodinâmica do trabalho. Rio de Janeiro: Fiocruz, 2011.

FIPE/MODEN: Monitoramento da Inserção da Pessoa com Deficiência no Mercado de Trabalho. Disponível em: <httpp/projeto.fipe.org.br/moden/Rais Emprego. aspx.> FURTADO, O. Trabalho e solidariedade. São Paulo: Cortez, 2011.

FUNDAÇAO SEADE. Pesquisas Municipais. www.seade.gov.br. Acesso em 6/6/2013, 05/07/2014 e 19/06/2016.

GOMES, M. H. S. C. Políticas Sociais: educação e desenvolvimento no contexto de uma municipalidade. Americana: Adônis, 2010.

GOMES, M. H. S. C. Inclusão da Pessoa com Deficiência no Mercado de Trabalho: gestão, direitos e efetividade. Tese de Doutorado. Universidade Municipal de São Caetano do Sul. São Paulo, 2014.

INSTITUTO BRASILEITO DE GEOGRAFIA e ESTATISTICA. IBGE/MUNIC/2012. KANT, I. Fundamentos da Metafísica dos Costumes. São Paulo: Abril Cultural, 1974.

KRELL, A. Discricionariedade administrativa e conceitos legais indeterminados. $2^{\text {a }}$ ed. Livraria do Advogado, 2013.

LIMA JUNIOR, J. B. Elementos constitutivos da ideia dos direitos humanos. In: Os direitos humanos econômicos, sociais e culturais. Rio de Janeiro. Renovar, 2001.

MAUSS, M. Ensaio sobre a dádiva: Forma e razão da troca nas sociedades arcaicas. In: Sociologia e Antropologia. São Paulo: Cosac Naify, 2003.

BRASIL: Ministério do Trabalho e Emprego, MTE/RAIS, 2007, 2008, 2009, 2010, 2011, 2013 e 2013, 20142015 e 2016.

MORIN, E. Os sentidos do Trabalho. RAE, v. 41, nº 3. Jul-Set. 2001. 
NUNES RIZATTO, L. A. O princípio constitucional da dignidade da pessoa humana. São Paulo: Saraiva, 2004.

SARLET, I. W. Dignidade da pessoa humana e direitos fundamentais. $6^{\mathrm{a}}$ ed. Porto Alegre: Livraria do Advogado, 2008.

SEN, A. Desenvolvimento como liberdade. São Paulo: Cia das Letras, 2000.

SUNDFELD, C. A. Fundamentos dos Direitos Públicos. São Paulo: Malheiros, 1992.

VYGOTSKY, L. Enfoque psicológico da educação pelo trabalho. In: Psicologia Pedagógica, 2a . ed. São Paulo: Martins Fontes, 2004. 